\title{
Evaluation of Formic Acid and Cyclohexylamine as Additives in Electrodeposition of Zn Coating
}

\author{
Carolina da Silva Lopes ${ }^{a *}$ (1), Paulo Moura de Santana ${ }^{a}$,Claudia Liziane Fanezi Rocha ${ }^{a}$, \\ Carlos Alberto Caldas de Souza $a^{a}$
}

\author{
${ }^{a}$ Universidade Federal da Bahia, Escola Politécnica, Laboratórios de Metais e Corrosão, Salvador, BA, Brasil
}

Received: October 29, 2019; Revised: March 23, 2020; Accepted: May 9, 2020

\begin{abstract}
The $\mathrm{Zn}$ coatings obtained through electrodeposition are used to protect steel substrates from corrosion. In general, organic additives are added to the deposition bath in order to improve deposition characteristics such as corrosion resistance, hardness and deposition efficiency. Despite of the literature present information about the various organic additives effects on $\mathrm{Zn}$ coating properties there is no analysis of organic compounds with free electron-containing radicals, such as formic acid and cyclohexylamine. The formic acid has oxygen atoms with free electrons, whereas cyclohexylamine contains nitrogen with free electrons. Aiming at overcoming this gap, this manuscript presents an analysis of the effect in addition of formic acid mixture and cyclohexylamine on the deposition flow efficiency, corrosion resistance, hardness, roughness and micro-structure of $\mathrm{Zn}$ coating on carbon steel AISI 1020. The corrosion resistance evaluation was performed by potentiodynamic polarization determined by polarization resistance and weight loss tests as well. The analisys of morphology and electrodeposited microstructures were made by the Scanning Electron Microscopy (SEM) and Spectrometry X-Ray Diffraction (XRD). The Zn coatings were obtained from chloride deposition baths at constant $\mathrm{pH}$ 5. Results showed that corrosion resistance in the $0.5 \mathrm{~mol} / \mathrm{L} \mathrm{NaCl}$ solution of $\mathrm{Zn}$ coatings increases with the addition of the mixture of the formic acid and / or cyclohexylamine. Also, the corrosion resistance is higher with mixture than with additives alone. The addition of the mixture formic acid and cyclohexylamine increases the basal plane presence $\left(\begin{array}{lll}0 & 0 & 2\end{array}\right)$. However, the basal plane presence $\left(\begin{array}{ll}0 & 0\end{array}\right)$ does not increase when formic acid and cyclohexylamine are added alone which indicates a synergic effect of formic acid and cyclohexylamine in in the plan promotion $\left(\begin{array}{ll}0 & 0\end{array}\right)$. Also, was observed that an addition of formic acid mixture and cyclohexylamine increases the current deposition efficiency, decreases the roughness and raises the $\mathrm{Zn}$ coating hardness.
\end{abstract}

Keywords: Electrodeposition, Zinc; Additives, Corrosion, Formic acid, Cyclohexylamine.

\section{Introduction}

$\mathrm{Zn}$ coatings obtained through electrodeposition are often used as sacrificial coatings for protecting ferrous materials against corrosion in diverse applications, such as steel sheets coating used in home appliances, tubes coating and fasteners. The $\mathrm{Zn}$ deposition by electrodeposition presents important advantages as, for instance, low cost, easy preparation of substrate surface, good surface finish, enables good adhesion of paint on its surface ${ }^{1}$.

The important disadvantage of $\mathrm{Zn}$ coating is the low corrosion resistance in aggressive environments. Among these environments are those containing chloride ions and the atmosphere containing industrial pollutants. An alternative to increase the corrosion resistance of $\mathrm{Zn}$ coating and, therefore, increase its useful life is the addition of organic additives in the bath deposition.

Organics additives modify characteristics of $\mathrm{Zn}$ deposit because they are adsorbed in deposit ${ }^{2}$. Initially the additive is preadsorbed on the metal substrate and is subsequently adsorbed on the coatings ${ }^{3}$. Adsorption of additive during electrodeposition occurs through radicals containing free

*e-mail: carolinalops@gmail.com electrons. Among these radicals are atoms of oxygen, nitrogen and sulfur. Oxygen acts on radicals for adsorption of additives such as gelatin, polyethylene glycol (PEG, urea and Saccharin, nitrogen radicals for adsorption of Stearyl dimethylbenzyl ammonium chloride [SDBAC] and saccharin, as $\mathrm{NH}$ radicals for adsorption of thiourea ${ }^{2,3}$. Although the effect of many additives on $\mathrm{Zn}$ deposit characteristics has been analyzed, there are organic compounds with free electron-containing radicals that have not been analyzed as additives in $\mathrm{Zn}$ electrodeposition. Among these compounds are formic acid and cyclohexylamine. Formic acid has oxygen atoms with free electrons, whereas cyclohexylamine contains nitrogen with free electrons. Therefore, it is possible that the absorption of these additives occurs in deposit through these free electrons. Cyclohexylamine is an amine frequently used as a corrosion inhibitor in petrochemical industry and there is no information in literature about the effect of this molecule on electrodeposits.

Besides the molecular structure there are other factors that make interesting the study of formic acid as additives in the process of electrodeposition of $\mathrm{Zn}$. Formic acid $(\mathrm{HCOOH})$ is an organic compound used as a component in 
bath deposition of chromium electrodeposits. In addition to acting as complexing agent for $\mathrm{Cr}$ (III) ${ }^{4}$ it was found that the addition of formic acid in bath deposition increases corrosion resistance of black chromium deposit and this effect is attributed to formation of a thin, compact, and amorphous coating.

In a prior work ${ }^{5}$ it was found that the addition of formic acid improves corrosion resistance of a $\mathrm{Zn}$-Ni electrodeposition. However, it was not clear if the deposit was more compact with addition of formic acid, but it was observed that this additive promotes formation of $\mathrm{Ni}_{5} \mathrm{Zn}_{21}$ intermetallic phase, which support the coating corrosion resistance improvement. Although in $\mathrm{Zn}$ coating does not occur formation of $\mathrm{Ni}_{5} \mathrm{Zn}_{21}$ intermetallic phase it is interesting to investigate if addition of formic acid affects presence of phases related to corrosion resistance of this coating.

In this sense, this paper investigate how galvanostatic deposition efficiency and characteristics of electrodeposited $\mathrm{Zn}$ coating on a steel substrate are affected by addition of acid formic mixture and cyclohexylamine. Besides this contribution, we also analyzed the current efficiency, the effect of these additives on structure, hardness, roughness and corrosion resistance of zinc coatings.

\section{Experimental Procedure}

In this work, the bath used for the electrodeposition process of Zinc has an acidic characteristic and is formed by three reagents with degree of purity P.A. The solution is composed of zinc chloride $\mathrm{PA}\left(\mathrm{ZnCl}_{2}\right)$ : substance containing the zinc ions that will be deposited, potassium chloride PA (KCL): substance that has the role of raising the conductivity of the medium, and also boric acid $\mathrm{PA}\left(\mathrm{H}_{3} \mathrm{BO}_{3}\right)$ : substance that maintains the $\mathrm{pH}$ of the solution close to 5 . In addition to these reagents, the electrodeposition bath also has the additives, formic acid and cyclohexylamine that would influence the structure, corrosion resistance and other characteristics of the tank. The reagents used are all of the brand Synth. The reagents were added to form the electrodeposition solution in 1L of distilled water. Each reagent was weighed in a digital analytical balance, with four decimal places of the brand ACCULAB model ALC-210.4. Table 1 shows the amount of additives in each bath.

Table 1. Amount of Formic Acid and Cyclohexylamine.

\begin{tabular}{ccc}
\hline Bath & $\begin{array}{c}\text { Amount of Formic Acid } \\
(\mathbf{m o l} / \mathbf{L})\end{array}$ & $\begin{array}{c}\text { Amount of } \\
\text { Cyclohexylamine } \\
(\mathbf{m o l} / \mathbf{L})\end{array}$ \\
\hline 1 & 0.03 & 0.0 \\
\hline 1 & 0.07 & 0.0 \\
\hline 1 & 0.13 & 0.0 \\
\hline 1 & 0.20 & 0.0 \\
\hline 2 & 0.0 & 0.9 \\
\hline 2 & 0.0 & 1.3 \\
\hline 2 & 0.0 & 1.5 \\
\hline 2 & 0.0 & 1.9 \\
\hline 3 & 0.03 & 0.9 \\
\hline 3 & 0.07 & 1.3 \\
\hline 3 & 0.13 & 1.5 \\
\hline 3 & 0.20 & 1.9 \\
\hline
\end{tabular}

The parameters used in the galvanostatic deposition were: room temperature; without agitation; current density $10 \mathrm{~mA} . \mathrm{cm}^{-2}$; graphite bar used as anode; electrodeposition time $34 \mathrm{~min}$; $5 \mu \mathrm{m}$ thick coating. The potentiodynamic deposition was made using an AUTOLAB Potentiostatic\&Galvanostatic model PGSTAT 100 instrument. O carbon steel 1020 were employed as working electrodes, $\mathrm{Hg} / \mathrm{Hg}_{2} \mathrm{Cl}_{2}$ (saturated calomel electrode - SCE) and graphite were employed as reference and auxiliary, respectively.

The galvanostatic deposition efficiency was evaluated by the ratio between the zinc electroplated mass and the theoretical mass 6 .

The effect of additives on the corrosion resistance of $\mathrm{Zn}$ coating was evaluated through mass loss and electrochemical tests. The corrosion rate was obtained through mass loss tests in $0.5 \mathrm{~mol} / \mathrm{L} \mathrm{NaCl}$ solution ( $\mathrm{pH}$ around 6.7). All values were obtained in triplicates. Through the electrochemical tests the polarization resistance ( $\mathrm{Rp}$ ) was obtained in $0.5 \mathrm{~mol} / \mathrm{L} \mathrm{NaCl}$ solution and potentiodynamic polarization curves in $2.0 \mathrm{~mol} / \mathrm{L}$ $\mathrm{NaOH}$. These measures were carried out in an electrochemical cell using the saturated Calomel $-\mathrm{Hg}_{2} \mid \mathrm{Hg}_{2} \mathrm{Cl}_{2}$ as the reference electrode and the graphite counter electrode using an AUTOLAB potentiostat/galvanostat model PGSTAT100, controlled by NOVA 1.11 software, using a scanning speed of $10 \mathrm{mV} / \mathrm{s}$.

The surface morphology at of the electrodeposits was obtained using a JEOL JSM - 6610LV scanning electron microscope (SEM). Roughness of the deposits was analyzed by Mitutoyo, SJ410 series. The hardness measurements were carried out in a microdurometer Model Shimazdu - HMV Series, with displacement $\pm 12.5 \mathrm{~mm}$ ( 0 to $25 \mathrm{~mm}$ ) for both axes ( $\mathrm{X}$ and $\mathrm{Y}$ ), movement speed of up to $2 \mathrm{~mm} / \mathrm{s}$ and accuracy in positioning between $0,02-10 \mathrm{~mm}$. The coating crystal phase structure was analyzed by X-ray diffraction (XRD) using a SHIMADZU XRD-6000 model instrument equipped with a $\mathrm{Cu}-\mathrm{K} \alpha$ radiation source $(40 \mathrm{kV}$ and $40 \mathrm{~mA})$.

\subsection{Results}

\section{Effect of additive on the corrosion resistance}

To studies the effect of the addition of the mixture of acid formic and cyclohexylamine on corrosion resistance of $\mathrm{Zn}$ coating were analyzed deposits obtained through deposition baths containing different concentrations of formic acid and cyclohexylamine. The $\mathrm{pH}$ of these deposition baths was maintained at 5, which corresponds to the $\mathrm{pH}$ of the bath in the absence of the additives studied.

Initially was analyzed the effects of formic acid addition (baths 1) and the effect of cyclohexylamine addition (baths 2) on the corrosion resistance of $\mathrm{Zn}$ deposit. The $\mathrm{Zn}$ deposits analyzed were obtained from baths deposition with same $\mathrm{pH}, 5$. The $\mathrm{pH}$ of deposition baths content formic acid was adjusted by potassium hydroxide addition (baths 1), and the $\mathrm{pH}$ of baths deposition content cyclohexylamine was adjusted by sulfonyl acid addition (baths 2 ) in comparation.

This effect of addition formic acid and/or cyclohexylamine on corrosion resistance of coatings was analyzed by mass loss measurements, potentiodynamic polarization curves and polarization resistance ( $\mathrm{Rp}$ ), obtained from potentiodynamic polarization curves. 
Figures 1 and 2 show the results of corrosion rate from mass loss test, corresponding an acid formic addition and cyclohexylamine addition, respectively. These figures also show the corrosion rates of coatings obtained from mixture of formic acid and cyclohexylamine addition (baths 3 ) and the corrosion rates of coating obtained in the absence of these additives.

Table 2 and 3 show the effect of addition of formic acid (baths 1) and the effect of addition of cyclohexylamine (baths 2) on polarization resistance, $\mathrm{Rp}$, respectively. These table also show the Rp of coatings obtained from the mixture of formic acid and cyclohexylamine addition (baths 3 ) and the $\mathrm{Rp}$ of coating obtained in the absence of these additives. The $\mathrm{Rp}$ values are related to the resistance of the electrodeposit to dissolution. Higher Rp values indicate enhanced corrosion resistance.

The results showed in Table 2 and 3 are consistent with obtained results from loss mass measurement and show that the addition of acid formic and cyclohexylamine increase corrosion resistance of $\mathrm{Zn}$ coating and this effect is larger with increasing these additive concentrations. The corrosion resistance of $\mathrm{Zn}$ coating is higher for a content of formic acid of $0.2 \mathrm{~mol} / \mathrm{L}$ and for a content of cyclohexylamine of $1.9 \mathrm{~mL}$. The addition of formic acid concentration above $0.2 \mathrm{~mol} / \mathrm{L}$ and of cyclohexylamine concentration above $1.9 \mathrm{~mL}$ results in a non-adherent electrodeposit on the substrate. The results obtained by mass loss and $\mathrm{Rp}$ show that the effect of formic acid addition on the increased corrosion resistance of $\mathrm{Zn}$ coating is higher than that caused by cyclohexylamine addition.

The presented results on Figures 1 and 2 and Tables 2 and 3 show the corresponding corrosion rate obtained by, respectively, mass loss measurements and polarization resistance of $\mathrm{Zn}$ coating obtained from bath deposition containing a mixture of different amounts of formic acid and cyclohexylamine. They showed that the effect of formic acid addition on increased corrosion resistance of $\mathrm{Zn}$ coating is higher than that caused by cyclohexylamine addition.

The results also show that the addition of mixture of formic acid and cyclohexylamine causes an increase in corrosion resistance of $\mathrm{Zn}$ coating higher than that caused by isolated addition of each of these additives, indicating presence of a synergistic effect between formic acid and cyclohexylamine. The increase in corrosion resistance is higher with the concentration of formic acid and cyclohexylamine concentration.

\subsection{Potentiodynamic Polarization}

Initially, potentiodynamic polarization curves of $\mathrm{Zn}$ coatings were obtained in $0.5 \mathrm{~mol} / \mathrm{L} \mathrm{NaCl}$ solution. In these curves, it was reported that the current density increases continuously with increase of potential in anodic direction indicating, therefore, absence of $\mathrm{Zn}$ deposits passivation in this solution, shown in Figure 3.

In a previous work ${ }^{7}$ the passive region was detected in $\mathrm{Zn}$ deposits polarized in $\mathrm{NaOH}$ solution. Figure 3 shows the potentiodynamic polarization curves obtained in $2.0 \mathrm{~mol} / \mathrm{L}$ solution of $\mathrm{NaOH}$ of $\mathrm{Zn}$ deposits obtained in absence and presence of formic acid mixture and cyclohexylamine contend different concentrations of these additives. These curves

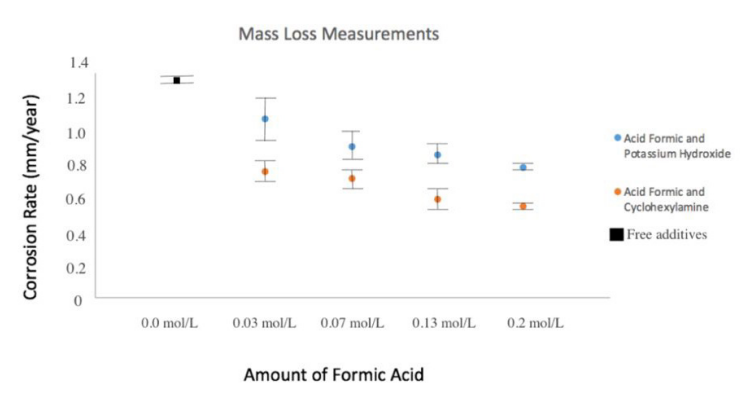

Figure 1. Corrosion rate obtained by mass loss measurement in $\mathrm{NaCl} 0.5 \mathrm{~mol} / \mathrm{L}$ of $\mathrm{Zn}$ deposit obtained in absence and presence of different concentrations of formic acid.

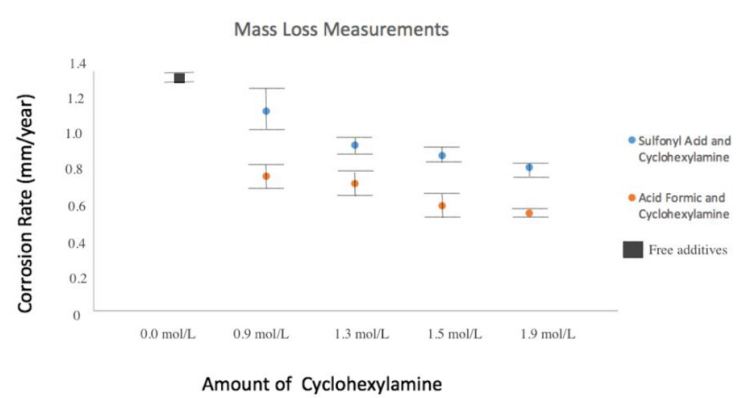

Figure 2. Corrosion rate obtained by mass loss measurement in $\mathrm{NaCl} 0.5 \mathrm{~mol} / \mathrm{L}$ of $\mathrm{Zn}$ deposit obtained in absence and presence of different concentrations of cyclohexylamine.

Table 2. Polarization resistance values in $\mathrm{NaCl} 0.5 \mathrm{~mol} / \mathrm{L}$ solution of $\mathrm{Zn}$ deposit obtained in absence and presence of different concentrations of formic acid. In baths 1: Formic Acid and Potassium Hydroxide and in baths 3: Mixture of Formic Acid and Cyclohexylamine.

\begin{tabular}{ccc}
\hline $\begin{array}{c}\text { Amount of Acid } \\
(\mathbf{m o l} / \mathbf{L})\end{array}$ & RP: Baths 1 $(\Omega)$ & RP: Baths 3 $(\Omega)$ \\
\hline 0 & 78.92 & 78.92 \\
\hline 0.03 & 108.57 & 111.325 \\
\hline 0.07 & 165.32 & 161.385 \\
\hline 0.13 & 188.39 & 223.78 \\
\hline 0.20 & 228 & 266.73 \\
\hline
\end{tabular}

Table 3. Polarization resistance values in $\mathrm{NaCl} 0.5 \mathrm{~mol} / \mathrm{L}$ solution of $\mathrm{Zn}$ deposit obtained in absence and presence of different concentrations of cyclohexylamine. In bath 2: Sulfonyl acid and Cyclohexylamine and in bath 3: Mixture of Formic Acid and Cyclohexylamine.

\begin{tabular}{ccc}
\hline $\begin{array}{c}\text { Amount of } \\
\text { Cyclohexylamine } \\
(\mathbf{m o l} / \mathbf{L})\end{array}$ & RP: Baths 2 $(\Omega)$ & RP: Baths 3 $(\Omega)$ \\
\hline 0 & 78.92 & 78.92 \\
\hline 0.9 & 85.26 & 111.325 \\
\hline 1.3 & 99.37 & 161.385 \\
\hline 1.5 & 103.76 & 223.78 \\
\hline 1.9 & 118 & 266.73 \\
\hline
\end{tabular}

indicate the occurrence of three distinct processes on zinc coating surface: active dissolution (region I), passivation (region II) and transpassivation (region III).

In region I initially occur the deposit active dissolution indicated by increase of current density with elevation of 


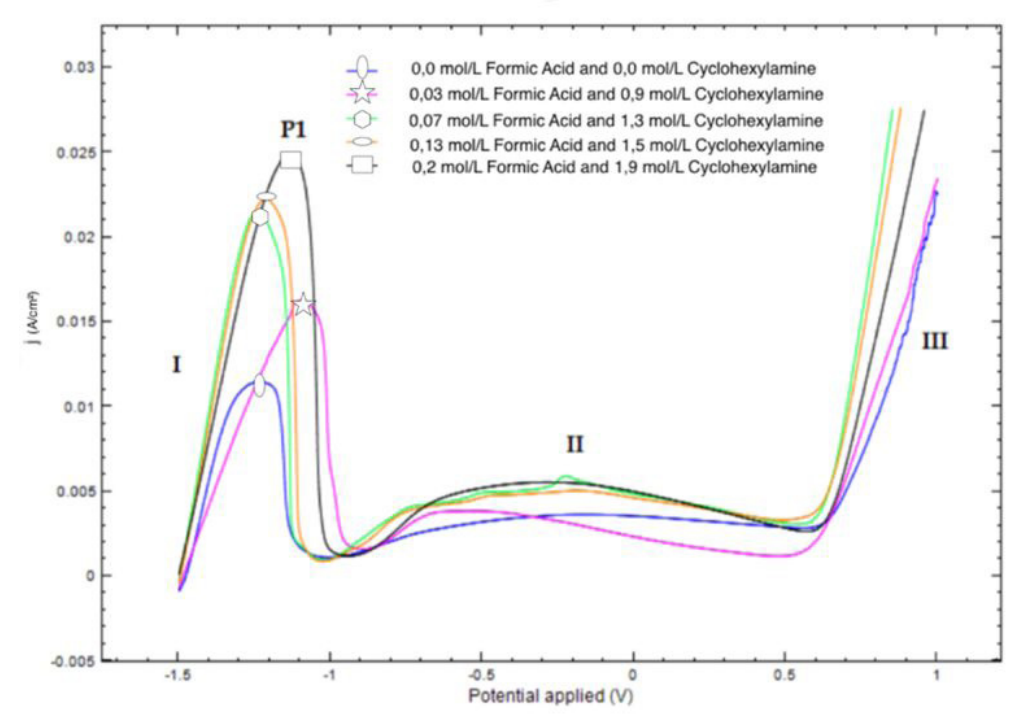

Figure 3. Potentiodynamic polarization curves of $\mathrm{Zn}$ coatings in $2.0 \mathrm{~mol} / \mathrm{L} \mathrm{NaOH}$ solution.

potential in anodic direction occurs. This increase in current density occurs until the peak (p1) from which a passive film is formed resulting in inhibition of dissolution and in consequent decrease of current density which remains stable over a large range of potential and is called a passive region. In region III is observed that current density and consequently the dissolution process again increases due to the rupture of passive film. This region is known as transpassive and the potential from which a significant increase in current density occurs is known as the potential for transpassivation.

The current density corresponding to $\mathrm{p} 1$ peak is known as the active / passive transition current density, ia/p, and is related to the amount of corrosion product required to form the passive film. Table 4 shows the values of $\mathrm{ia} / \mathrm{p}$ and $\mathrm{Ea} / \mathrm{p}$ (potential corresponding to $\mathrm{p} 1$ peak). This table shows that $\mathrm{ia} / \mathrm{p}$ increase with the addition of acid formic and cyclohexylamine which indicates that in the presence of these additives a greater amount of corrosion product is required to form the passive film, and in relation to $\mathrm{Ea} / \mathrm{p}$ the results indicate that there is no clear trend between this parameter and the composition of the coatings analyzed.

A lower current density in passive region (region I) indicates a larger capacity of the passive film to inhibit the dissolution process, and a higher potential transpassivation indicates a passive film more resistant to breakage. As shown in Figure 3, the addition of mixture of formic acid and cyclohexylamine, except the addition of $0.03 \mathrm{~mol} / \mathrm{L}$ of formic acid and $0.9 \mathrm{~mL}$ of cyclohexylamine, increases the current density in passive region in potentials greater than $-0.3 \mathrm{~V}$ vs. $\mathrm{Hg} 2 \mathrm{O} 2$, however does not affect the potential transpassivation. Therefore, the addition of does not have an effect clear on the protective performance of passive films of $\mathrm{Zn}$ coatings.

\subsection{Morphology and topography}

The effect of addition of additives on the morphology and topography of the $\mathrm{Zn}$ deposit was analyzed by scanning electron microscopy and by roughness, respectively. The $\mathrm{Zn}$ deposits were obtained from bath deposition with the same $\mathrm{pH}$,
Table 4. Current density $i_{a / p}$ and potential $E_{a / p}$ data at active / passive transition peak.

\begin{tabular}{cccc}
\hline $\begin{array}{c}\text { Amount of } \\
\text { Formic Acid } \\
(\mathbf{m o l} / \mathbf{L})\end{array}$ & $\begin{array}{c}\text { Amount of } \\
\text { Cyclohexylamine } \\
(\mathbf{m o l} / \mathbf{L})\end{array}$ & $\mathbf{i}_{\mathbf{a} / \mathbf{p}}\left(\mathbf{A} / \mathbf{c m}^{2}\right)$ & $\begin{array}{c}\mathbf{E}_{\mathrm{a} / \mathbf{p}}(\mathbf{V}) \mathbf{v s} . \\
\mathrm{Hg}_{2} \mathrm{O}_{2}\end{array}$ \\
\hline 0 & 0 & 0.0112 & -1.24 \\
\hline 0.03 & 0.9 & 0.0159 & -1.1 \\
\hline 0.07 & 1.3 & 0.0215 & -1.22 \\
\hline 0.13 & 1.5 & 0.0220 & -1.2 \\
\hline 0.20 & 1.9 & 0.0248 & -1.12 \\
\hline
\end{tabular}

(around 5). Figure 4 shows the SEM micrographs of coating obtained in the presence formic acid $(0.2 \mathrm{~mol} / \mathrm{L}$ of formic acid adjusted by potassium hydroxide addition), and in the presence cyclohexylamine $(1.9 \mathrm{~mol} / \mathrm{L}$ of cyclohexylamine adjusted by sulfonyl acid).

The SEM micrographs in Figure 4 show that the addition of additives has an effect on the morphology of zinc coating. These micrographs indicate that the addition of cyclohexylamine results in the formation of a more compact coating, however it is not clear how the addition of formic acid affects the level of compaction of the coating.

Figure 5 shows SEM micrographs of coatings obtained in absence and presence of mixture of formic acid and cyclohexylamine with different concentrations of these additives.

That addition of mixture of formic acid and cyclohexylamine alters the morphology of coating both with respect to the coating obtained in absence of additives and with respect to the coatings obtained in presence of each of these added additives alone. The micrographs in Figure 6 show that it is not clear how the addition of different concentrations of formic acid mixture and cyclohexylamine affects the level of coatings compaction.

\subsection{Effect on roughness and hardness of Zn coating}

In order to analyze the effect of the addition of formic acid mixture and cyclohexylamine on level of $\mathrm{Zn}$ coating compaction, roughness measurements of coatings were 


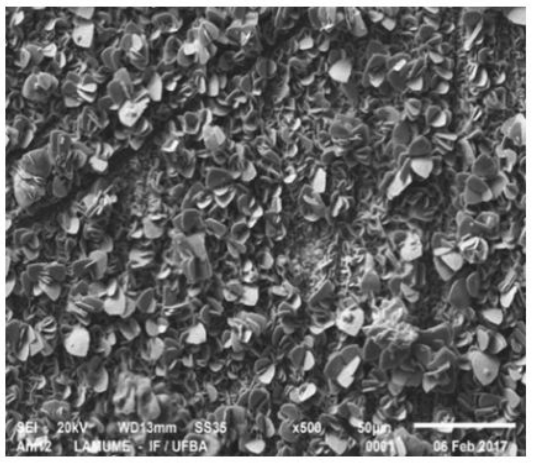

a)

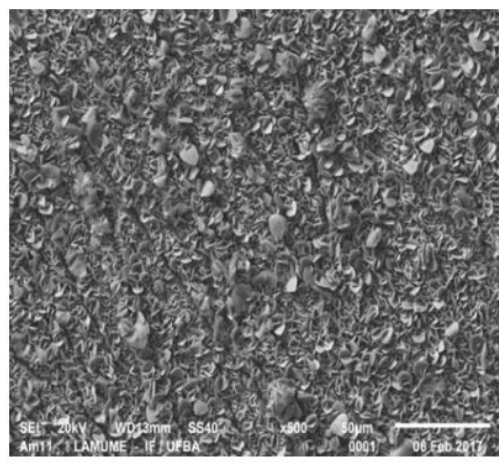

b)

Figure 4. SEM of zinc electroplated steel AISI 1020. Micrograph of Zn coating obtained from an electrodeposition bath 2 (5-a), containing $0.2 \mathrm{~mol} / \mathrm{L}$ of formic acid adjusted by potassium hydroxide addition and bath $3(5-\mathrm{b})$ containing $1.9 \mathrm{~mol} / \mathrm{L}$ of cyclohexylamine adjusted by sulfonyl acid.

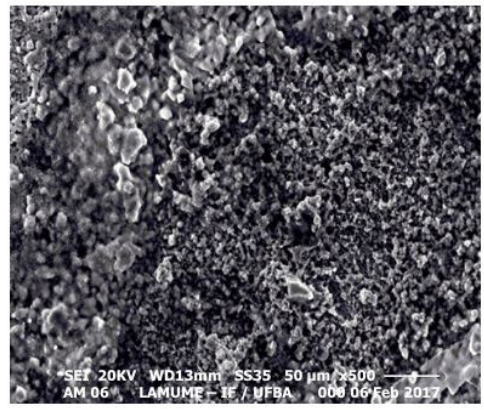

a)

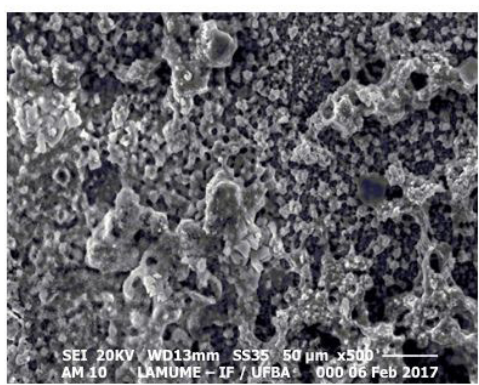

c)

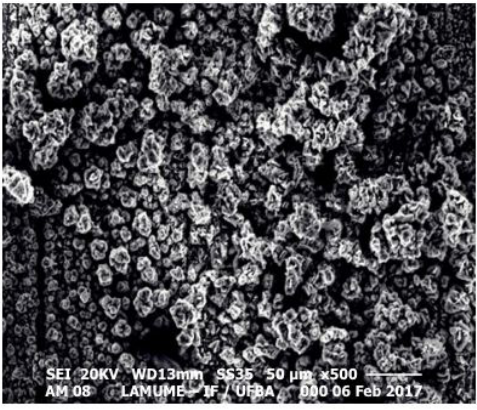

b)

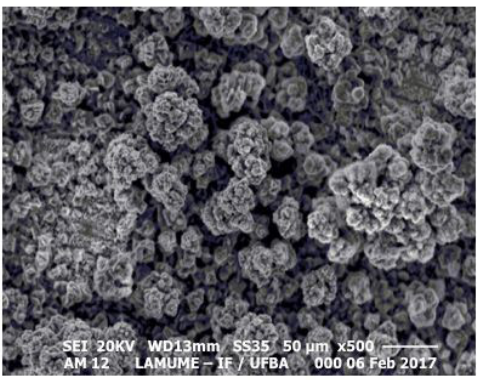

d)

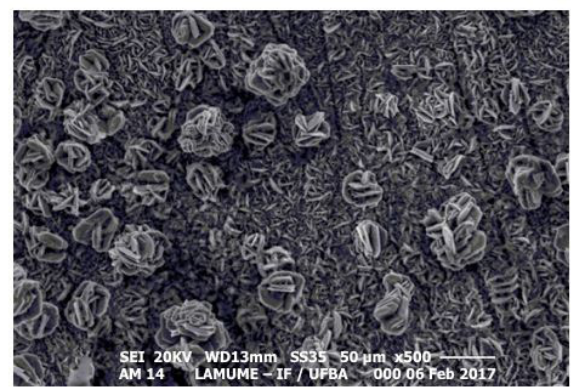

e)

Figure 5. SEM micrographs of coatings (500x). Containing $0.0 \mathrm{~mol} / \mathrm{L}$ Formic Acid and $0.0 \mathrm{~mol} / \mathrm{L}$ Cyclohexylamine $(6-\mathrm{a}), 0.03 \mathrm{~mol} / \mathrm{L}$ Formic Acid and $0.9 \mathrm{~mol} / \mathrm{L}$ Cyclohexylamine (6-b), $0.07 \mathrm{~mol} / \mathrm{L}$ Formic Acid and $1.3 \mathrm{~mol} / \mathrm{L}$ Cyclohexylamine (6-c), $0.13 \mathrm{~mol} / \mathrm{L} \mathrm{Formic}$ Acid and $1.5 \mathrm{~mol} / \mathrm{L}$ Cyclohexylamine (6-d), $0.2 \mathrm{~mol} / \mathrm{L}$ Formic Acid and $1.9 \mathrm{~mol} / \mathrm{L}$ Cyclohexylamine (6-e). 


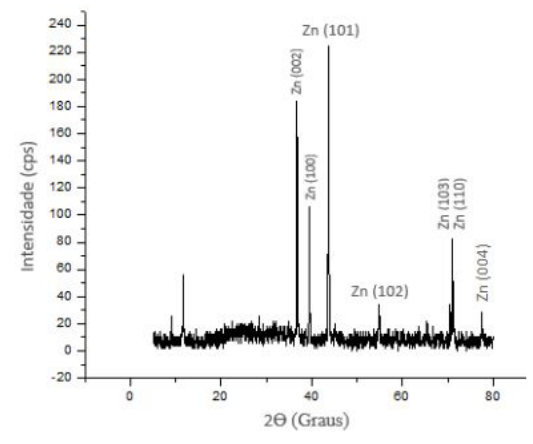

a)

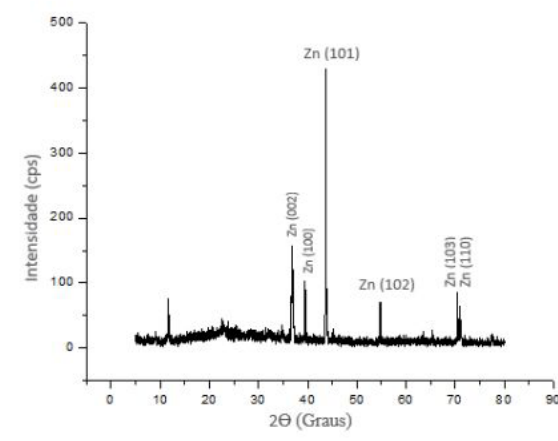

b)

Figure 6. Diffractograms of $\mathrm{Zn}$ coatings obtained by deposition baths at $\mathrm{pH} 5$ in electrodeposition bath 1 (5-a), containing $0.2 \mathrm{~mol} / \mathrm{L}$ of formic acid adjusted by potassium hydroxide addition and bath 2 (5-b) containing $1.9 \mathrm{~mol} / \mathrm{L}$ of cyclohexylamine adjusted by sulfonyl acid.

Table 5. Roughness values of $\mathrm{Zn}$ coatings and Hardness with the addition of the mixture of the acid formic and cyclohexylamine.

\begin{tabular}{lcc}
\hline \multicolumn{1}{c}{ Specimens } & Roughness/ $\boldsymbol{\mu m}$ & Hardness $\left(\mathbf{K g f} / \mathbf{m m}^{2}\right)$ \\
\hline Coating free additive & $1.75+/-0.065$ & $60.55+/-3.10$ \\
\hline Coating $(0.03 \mathrm{~mol} / \mathrm{L}$ Formic Acid and 0.9 mol/L Cyclohexylamine) & $1.14+/-0.065$ & $73.71+/-3.2$ \\
\hline Coating $(0.07 \mathrm{~mol} / \mathrm{L}$ Formic Acid and $1.3 \mathrm{~mol} / \mathrm{L}$ Cyclohexylamine) & $0.53+/-0.060$ & $75.70+/-2.0$ \\
\hline Coating $(0.13 \mathrm{~mol} / \mathrm{L}$ Formic Acid and $1.5 \mathrm{~mol} / \mathrm{L}$ Cyclohexylamine $)$ & $0.49+/-0.060$ & $79.69+/-3.10$ \\
\hline Coating $(0.2 \mathrm{~mol} / \mathrm{L}$ Formic Acid and $1.9 \mathrm{~mol} / \mathrm{L}$ Cyclohexylamine $)$ & $0.39+/-0.048$ & $124.37+/-4.0$ \\
\hline
\end{tabular}

obtained. In Table 5 are listed the roughness values of $\mathrm{Zn}$ coatings in absence and presence of different concentrations of mixture of formic acid and cyclohexylamine. These values show that the addition of this mixture decreases roughness of $\mathrm{Zn}$ deposit indicating presence of these additive results in a more compact deposit ${ }^{8}$ and that this effect is higher with increasing concentration of the additives.

The increase in the level of $\mathrm{Zn}$ coating compaction caused by addition of mixture of formic acid and cyclohexylamine is consistent with the results showing the increase in corrosion resistance of $\mathrm{Zn}$ coating caused by addition of this mixture, since the coating roughness reduction implies a decrease in the coating contact area with the corrosive environment thus favoring the corrosion resistance.

To analyze the effect of mixture of formic acid and cyclohexylamine addition on grain refining and hardness of $\mathrm{Zn}$ deposits microhardness was measured in baths obtained from bath deposition with $\mathrm{pH} 5$ and content different concentrations of these additives. These results are reported in Table 5 and show that hardness of $\mathrm{Zn}$ coating increases with addition of cyclohexylamine formic acid and this effect is more significant with increasing concentration of these additives.

The increase of hardness with addition of formic acid mixture and cyclohexylamine reported in Table 5 is probably related to decrease of grain size of coating, which increases the grain boundary area by volume. Grain boundaries hinder the propagation of dislocations through a material and thus the decrease in grain size hinders the propagation of discordances which results in increase of material hardness. Therefore, the results obtained through hardness test indicate that addition of formic acid mixture and cyclohexylamine resulted in a decrease in grain size.
The increase in hardness of $\mathrm{Zn}$ coating with addition of mixture of formic acid and cyclohexylamine in bath deposition indicates that the presence of these additives tends to increase resistance to wear by deposit abrasion. This effect will be verified in future work through specific abrasion wear evaluation tests; however, the results indicate that combined effect of formic acid and cyclohexylamine on increase of mechanical fatigue strength of $\mathrm{Zn}$ coating is promising.

\subsection{Crystallographic orientation}

Figure 6 shows the X-ray diffractograms of Zn deposits obtained by deposition baths at $\mathrm{pH}$ 5. (6-a), in presence of $0.2 \mathrm{~mol} / \mathrm{L}$ of formic acid, (7-b) and in the presence of $1.9 \mathrm{~mol} / \mathrm{L}$ of cyclohexylamine.

Figure 7 show diffractograms obtained for deposits prepared in bath deposition content a mixture of formic acid and cyclohexylamine with different concentrations of these additive.

It is observed in Figures 6 and 7, that diffractograms peaks are formed by thin peaks, which indicates presence of crystalline structure. The presence of carbon in electrodeposit can promote formation of an amorphous structure. The amorphous structure can exhibit a higher corrosion resistance in comparison with crystalline structure ${ }^{9}$. However, the X-ray diffraction patterns show that despite carbon contained in formic acid and cyclohexylamine the addition of these additive maintained the coating crystal structure.

To determine the effect of additives addition on crystallographic orientation of electrodeposit, texture co-efficient (RTC, \%) was calculated for each of diffraction pattern peaks. The corresponding $R T C$ values are shown as a bar diagram in Figure 8 and 9. 


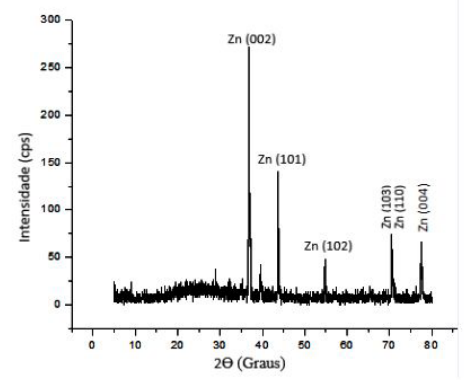

a)

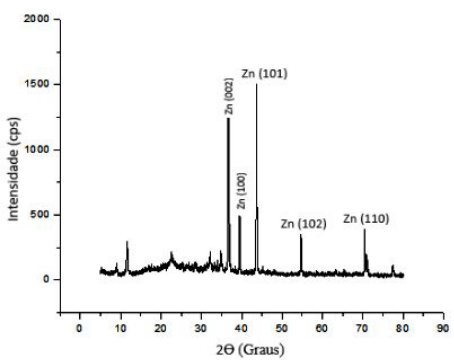

c)

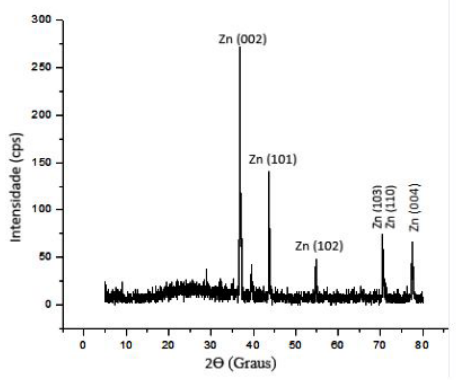

b)

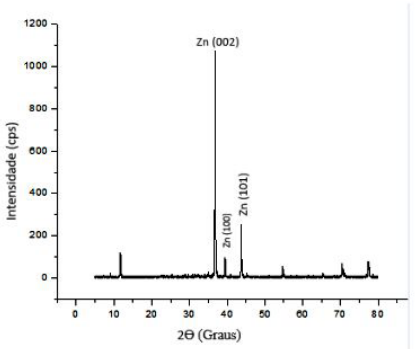

d)

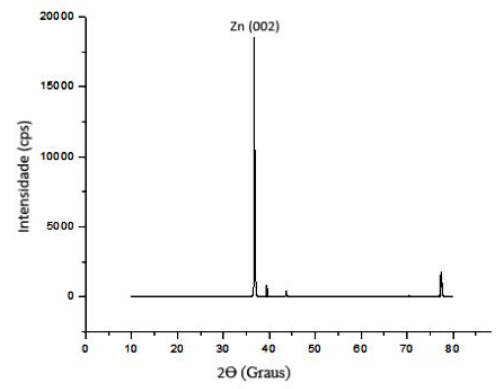

e)

Figure 7. Diffractograms of $\mathrm{Zn}$ coatings obtained by deposition baths at $\mathrm{pH} 5$ in absence and presence of different concentrations of the mixture of formic acid and cyclohexylamine. In (8-a) Free additive. In (8-b) Coating $0.03 \mathrm{~mol} / \mathrm{L}$ Formic Acid and 0.9 mol/L Cyclohexylamine). In (8-c) $0.07 \mathrm{~mol} / \mathrm{L}$ Formic Acid and $1.3 \mathrm{~mol} / \mathrm{L}$ Cyclohexylamine. In (8-d) $0.13 \mathrm{~mol} / \mathrm{L}$ Formic Acid and $1.5 \mathrm{~mol} / \mathrm{L}$ Cyclohexylamine. In (8-e) $0.2 \mathrm{~mol} / \mathrm{L}$ Formic Acid and $1.9 \mathrm{~mol} / \mathrm{L}$ Cyclohexylamine.

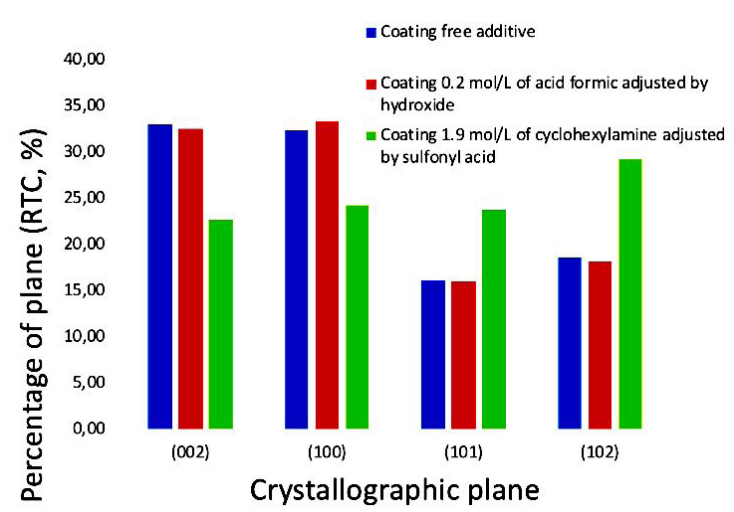

Figure 8. Percentage of RTC as a function of crystallographic planes of $\mathrm{Zn}$ coating obtained in the absence of additive, of coating obtained in the presence of $0.2 \mathrm{~mol} / \mathrm{L}$ of formic acid and of coating obtained in the presence of $1.9 \mathrm{~mol} / \mathrm{L}$ of cyclohexylamine.

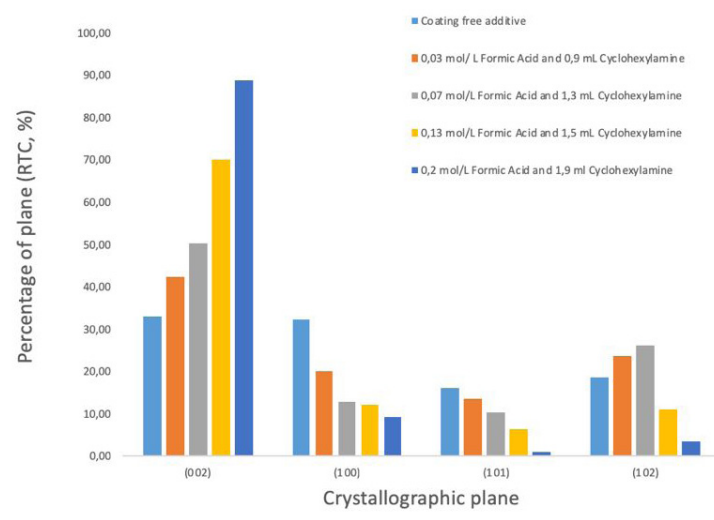

Figure 9. Percentage of RTC as a function of crystallographic planes of $\mathrm{Zn}$ coatings obtained in the absence and presence of the mixture of formic acid and cyclohexylamine containing various concentrations of these additives. 


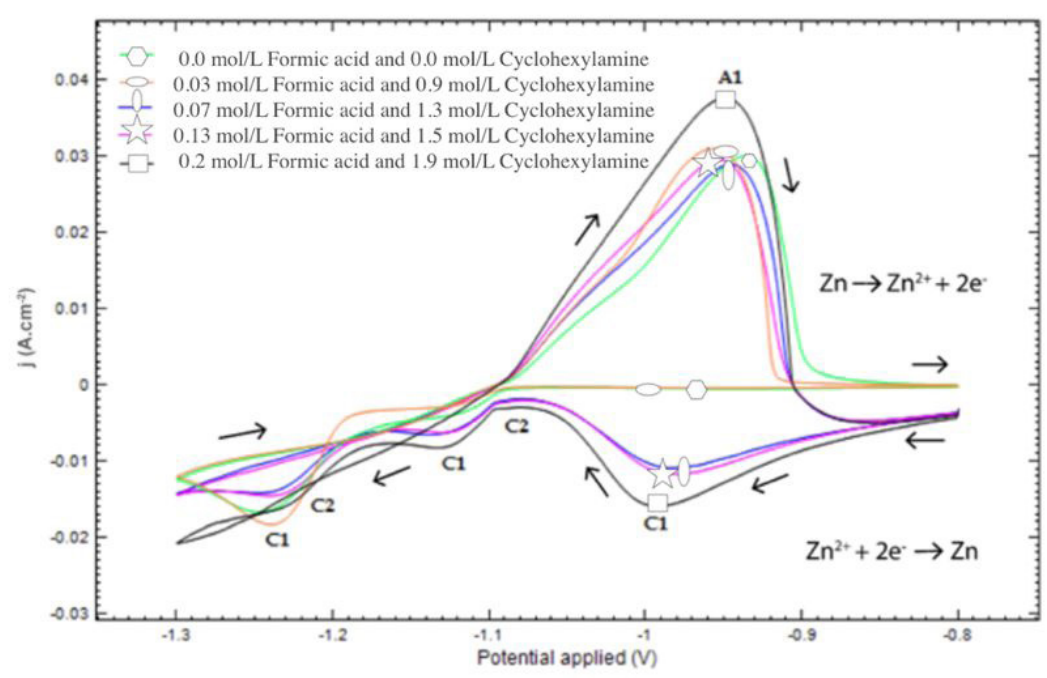

Figure 10. Potentiodynamic deposition curves obtained in absence and presence of formic acid mixture and cyclohexylamine with different concentrations.

Table 6. Effect of adittion of mixture of acid formic and ciclohexylamine in the deposition bath on the current efficiency (CE) of the Zn coating.

\begin{tabular}{ccccc}
\hline Formic acid (mol/L) & $\begin{array}{c}\text { Cyclohexylamine } \\
(\mathbf{m o l} / \mathbf{L})\end{array}$ & \% E Max & \% E Min & \% E Media \\
\hline 0 & 0.0 & 86.6 & 85.13 & 85.86 \\
\hline 0.03 & 0.9 & 87.92 & 86.52 & 87.45 \\
\hline 0.07 & 1.3 & 89.31 & 87.92 & 88.85 \\
\hline 0.13 & 1.5 & 90.71 & 87.92 & 89.31 \\
\hline 0.2 & 1.9 & 90.71 & 89.31 & 90.24 \\
\hline
\end{tabular}

It was observed in Figure 10 that RTC values of basal plane $\left(\begin{array}{lll}0 & 0 & 2\end{array}\right)$ increases while RTC values of pyramidal $\left(\begin{array}{lll}1 & 0 & 1\end{array}\right)$ and prismatic planes $\left(\begin{array}{lll}1 & 0 & 0\end{array}\right)$ decreases in coatings obtained from deposition baths containing mixture of formic acid and cyclohexylamine. This effect is more intense with increase of these additives concentration. However, the Figure 8 shows that the RTC values of basal plane $\left(\begin{array}{lll}0 & 0 & 2\end{array}\right)$ does not increase when formic acid and cyclohexylamine are added alone. This figure also shows that RTC values of pyramidal plane $\left(\begin{array}{lll}1 & 0 & 1\end{array}\right)$ decreases with addition of formic acid but increases with addition of cyclohexylamine. In relation to effect of additives addition on RTC values of pyramidal planes $\left(\begin{array}{lll}1 & 0 & 2\end{array}\right)$, the Figure 9 indicates that there is no clear trend in this regard.

\subsection{Zn electrodeposition current efficiency}

Table 6 shows the addiction effect of mixture of acid formic and cyclohexylamine in deposition bath on current efficiency (CE) of $\mathrm{Zn}$ galvanostatic electrodeposition. The $\mathrm{pH}$ of deposition bath was maintained 5 to analyze the addiction effect of additives on current efficiency regardless of $\mathrm{pH}$. The results in Table 6 show that addition of mixture of formic acid and cyclohexylamine increases the CE in comparison with absence of additives and $\mathrm{CE}$ increases with concentration of these additives.

To know the influence of formic and cyclohexylamine mixture on $\mathrm{Zn}$ deposition process, curves of potentiodynamic polarization were obtained in different deposition baths.

\subsection{Potentiodynamic deposition}

Figure 10 shown potentiodynamic deposition curves obtained in absence and presence of formic acid mixture and cyclohexylamine with different concentrations. The test was carried out with control of potential starting the scan around $0.8 \mathrm{Vvs}$. SCE. with inversion of potential towards anode region in $-1.3 \mathrm{Vvs}$. SCE., ending the scan in -0.8 Vvs. SCE.

The curves in Figure 10 show the occurrence of two cathode peaks $(\mathrm{C} 1$ and $\mathrm{C} 1)$ in curves corresponding to $\mathrm{Zn}$ deposits obtained in absence and presence of the additives mixture containing $0.03 \mathrm{~mol} / \mathrm{L}$ of formic acid and $0.9 \mathrm{~mol} / \mathrm{L}$ of cyclohexylamine. The three peaks ( $\mathrm{C} 2, \mathrm{C} 2{ }^{\prime}$ and $\left.\mathrm{C} 2{ }^{\prime}{ }^{\prime}\right)$ in curves corresponding to coatings obtained in presence of mixture of these additives with higher concentrations. These peaks correspond to $\mathrm{Zn}$ deposition and the presence of several peaks indicates that deposition occurs in several steps.

It is also seen from Figure 10 that the potential at which $\mathrm{Zn}$ deposition begins is significantly altered with addition of mixture with concentrations of formic acid and cyclohexylamine from $0.07 \mathrm{~mol} / \mathrm{L}$ and $1.3 \mathrm{~mol} / \mathrm{L}$ respectively. In the absence of additives and in presence of mixture containing $0.03 \mathrm{~mol} / \mathrm{L}$ of formic acid and $0.9 \mathrm{~mol} / \mathrm{L}$ of cyclohexylamine, the $\mathrm{Zn}$ deposition starts at potential of $-1.10 \mathrm{Vvs}$. SCE. whereas in presence of additives with higher concentrations the deposition starts from of a potential around - $0.8 \mathrm{Vvs}$. SCE. Therefore, this behavior indicates that the $\mathrm{Zn}$ deposition reaction 
$(\mathrm{Zn}+2+2 \mathrm{e} \rightarrow \mathrm{Zn})$ is significantly influenced by addition of this mixture.

In relation to anodic region is observed through Figure 10 the presence of a single peak, which corresponds to dissolution of $\mathrm{Zn}$ deposit. This behavior indicates that dissolution process of $\mathrm{Zn}$ deposit occurs in a single step independent of addition of the additive mixture.

\section{Discussion}

The crystallographic orientations of zinc polycrystalline grains might have effect on corrosion rates. In plans with highest packing density the activation energy required to dissolve the deposit is higher because the atoms have a higher number of nearest neighbors available for binding ${ }^{10}$. The packing density of zinc crystallographic planes increases in following order $\left(\begin{array}{lll}h & 0 & 0\end{array}\right)<\left(\begin{array}{lll}h & k & 0\end{array}\right)<\left(\begin{array}{lll}0 & 0 & l\end{array}\right)^{11 .}$. The basal plane $\left(\begin{array}{lll}0 & 0 & 2\end{array}\right)$ orientation exhibit a high packing density compared with other planes present in electrodeposit and higher percentage of this basal plane contribute for enhanced corrosion resistances of $\mathrm{Zn}$ coating ${ }^{2}$.

Therefore, the increase of basal plane $\left(\begin{array}{lll}0 & 0 & 2\end{array}\right)$ orientation and decrease of prismatic planes $\left(\begin{array}{lll}1 & 0 & 0\end{array}\right)$ orientation with addition of mixture of formic acid and cyclohexylamine contributes to elevation of $\mathrm{Zn}$ coating corrosion resistance. The increase in $\mathrm{Zn}$ coating corrosion resistance with the increase of formic acid and cyclohexylamine concentrations in bath deposition can be attributed to elevation of RTC values of $\left(\begin{array}{ll}0 & 0\end{array}\right)$ plans. However, in coatings obtained from bath deposition containing each of these additives alone, the increase of RTC values of ( $\left.\begin{array}{lll}0 & 0\end{array}\right)$ planes do not occur, which explains lower corrosion resistance of these coatings.

It is proposed ${ }^{12}$ that the basal plane $\left(\begin{array}{lll}0 & 0\end{array}\right)$, which has the lowest energy of formation, is developed at low overpotential (potential near equilibrium), and the lower packed planes and, therefore, with higher energy formation are developed in the high overpotentials. Therefore, RTC values increasement of basal plane $\left(\begin{array}{lll}0 & 0\end{array}\right)$ may be attributed to the decrease of overpotential for zinc deposition caused by addition of formic acid mixture and cyclohexylamine. This behavior is consistent with curves referring to the potenciodynamic deposition reported in Figure 10. This figure shows that with addition of higher concentrations of formic acid mixture and cyclohexylamine the $\mathrm{Zn}$ deposition starts at a less cathodic potential in relation to obtained deposit in absence or presence of a low content of these additives ( $0.03 \mathrm{~mol} / \mathrm{L}$ formic acid and $0.9 \mathrm{~mol} / \mathrm{L}$ cyclohexylamine).

It is found ${ }^{2}$ that the addition of organic additives such as polyvinyl alcohol (PVA) raises Zn coating corrosion resistance and this effect is attributed to increased presence of basal plane $\left(\begin{array}{lll}0 & 0 & 2\end{array}\right)$ caused by this additive. However, piperone addition in a bath containing PVA, although decreasing the intensity of basal plane ( $\left.\begin{array}{llll}0 & 0\end{array}\right)$ raises $\mathrm{Zn}$ deposit corrosion resistance $^{2}$. Therefore, this behavior shows that other effects such as a lower surface roughness may prevail over the plane texture. Similar behavior is found in present work, since addition of formic acid alone or only cyclohexylamine raises the $\mathrm{Zn}$ coating corrosion resistance but does not increase the intensity of basal plane ( 002 ), including the addition of cyclohexylamine only decreases the intensity of this plan.
Additive effect on grain refining is related to the effect on nucleation rate and grain growth. It has been proposed that higher cathode overpotential increases free energy to form new nuclei which results in a higher nucleation rate and consequently in higher grain refine ${ }^{13}$. This behavior was found ${ }^{14}$ with the addition in chlorite-plate solution of mixtures of polyacrylamide and thiourea polyacrylamide and in sulfate-plate solution with the mixture of thiourea and benzalacetone ${ }^{15}$. On the other hand, as previously seen, addition of mixture of formic acid and cyclohexylamine support the formation in the $\mathrm{Zn}$ deposit of the plane $\left(\begin{array}{lll}0 & 0\end{array}\right)$, which tends to occur in a smaller cathodic overpotential, as observed in Figure 3. The occurrence of $\mathrm{Zn}$ coating grain refining caused by addition of organic additives without causing overpotential cathode also was found ${ }^{3}$ with addition of saccharin and also with addition of sodium lauryl sulfate, which causes grain refining without altering the overpotential cathode. This apparent contradiction may be explained by the fact that the decrease in grain size caused by addition of additives does not occur only because of nucleation rate elevation and may also occur due to inhibition of the grains growth. It is possible that the addition of mixture of formic acid and cyclohexylamine causes inhibition of $\mathrm{Zn}$ grains growth without altering the nucleation rate. Additive additives can be adsorbed on $\mathrm{Zn}$ growth sites $^{3}$ causing the inhibition of $\mathrm{Zn}$ normal lateral growth. It is also possible that additives on cathode act as a physical barrier to $\mathrm{Zn}$ ions movement by reducing mobility of these ions and thus inhibiting grain growth ${ }^{13,16}$.

It has been proposed that grain refinement of $\mathrm{Zn}$ coating raises protective capacity of $\mathrm{ZnO}$ passive film thus increasing $\mathrm{Zn}$ coating corrosion resistance in enviroment which this passive film is formed. This behavior was found ${ }^{17}$ with addition of organic additives CTAB (cetyltrimethyl ammonium bromide) + VV (veratraldehyde) in Zn coatings and is attributed to increase in the nucleation rate of $\mathrm{ZnO}$ due to grain refining. These $\mathrm{Zn}$ coatings were obtained by pulse reverse current (PRC) which results in a high grain refine. However, results reported in Figure 3 show that the addition of formic acid mixture and cyclohexylamine does not increase protective performance of $\mathrm{ZnO}$ passive films. It is possible that the refining of grains caused by addition of mixture and cyclohylamine was not sufficient to increase the number of active nucleation sites of $\mathrm{ZnO}$ on coating surface at sufficient intensity to accelerate formation of passive $\mathrm{ZnO}$ film.

The change caused by the addition of formic acid and also by the addition of cyclohexylamine in morphology and corrosion resistance indicates that the adsorption of these additives occurred in Zn coating. Probably the adsorption of formic acid occurred through free electrons present in oxygen and the adsorption of cyclohexylamine through free electrons of $\mathrm{N}$. Considering that radical adsorption with more electrons interacts more intensively with substrate or zinc coating ${ }^{2}$ it is possible that the adsorption of formic acid having an oxygen radical containing 4 free electrons is more intense than that of cyclohexylamine with the $\mathrm{NH} 2$ radical containing 2 free electrons. Therefore, it is possible that the more intense adsorption of formic acid is related to higher $\mathrm{Zn}$ coatings corrosion resistance containing this additive in relation to coatings containing cyclohexylamine. 


\section{As previously seen (1. Introduction)}

The effect of organic additives in current efficiency $\mathrm{CE}$ of $\mathrm{Zn}$ deposition is generally related to the effect of additive on conductivity of electrolyte, hydrogen release reaction, and potential in which the deposition takes place ${ }^{18-21}$. As previously reported, the deposition was obtained from a deposition bath with a $\mathrm{pH}$ of 5 , with no significant effect of adding additives in deposition bath conductivity. It is found ${ }^{18}$ that the addition of gelatin in a $\mathrm{ZnCl}$ acid bath raises current efficiency of $\mathrm{Zn}$ coatings. This effect is attributed to the fact that this additive promotes the plane presence $\left(\begin{array}{lll}1 & 1 & 0\end{array}\right)$ that presents a smaller amount of defects, which act as active sites for adsorption of hydrogen. Therefore, the reduction of defects decreases the intensity of hydrogen evolution reaction, which favors the increase of current efficiency. It is possible that the addition of formic acid mixture and cyclohexlamine has a similar effect to that of gelatin in $\mathrm{CE}$ elevation, since addition of this mixture promotes the plane formation $\left(\begin{array}{lll}0 & 0\end{array}\right)$ which is more compact and therefore has fewer defects ${ }^{2}$ inhibiting hdrogen evolution.

It is also possible that the addition of mixture of formic acid and cyclohexylamine has caused the displacement of $\mathrm{Zn}$ nucleation potential to a cathodic overpotential range in which the deposition efficiency is maximal, thus increasing deposition efficiency. This possibility is supported by curves referring to potentiodynamic deposition Figure 10, which shows that the addition of formic acid mixture and cyclohexylamine with concentrations from $0.07 \mathrm{~mol} / \mathrm{L}$ and $1.3 \mathrm{~mol} / \mathrm{L}$, respectively, changes the potential from which $\mathrm{Zn}$ deposition occurs. The non-occurrence of difference in the deposition potential of mixtures with higher additive concentration indicates that the effect of these additives on deposition efficiency is not only based on deposition potential but also depends on another effect, such as the additives effect on plane formation $\left(\begin{array}{lll}0 & 0\end{array}\right)$.

\section{Conclusion}

It was found that corrosion resistance in $0.5 \mathrm{~mol} / \mathrm{L} \mathrm{NaCl}$ solution of $\mathrm{Zn}$ coatings obtained from chloride-containing deposition baths at constant $\mathrm{pH} 5$ increases with addition of formic acid and / or cyclohexylamine. The corrosion resistance was greatest in $\mathrm{Zn}$ coating obtained in presence of mixture of formic acid and cyclohexylamine in comparison with coatings obtained from baths containing each of these additives.

The corrosion resistance of the $\mathrm{Zn}$ coating increases with concentration of additives in mixture and is higher for a mixture of $0.2 \mathrm{~mol} / \mathrm{L}$ formic acid and $1.9 \mathrm{~mol} / \mathrm{L}$ cyclohexylamine. The addition of mixture with a higher concentration of additives results in a non-adherent coating to the substrate.

$\mathrm{X}$-ray diffraction shows that the addition of formic acid mixture and cyclohexylamine increases the basal plane presence $\left(\begin{array}{lll}0 & 0 & 2\end{array}\right)$ which is more compact compared to other planes, thus favoring $\mathrm{Zn}$ coating corrosion resistance. This effect is more intense with increase of concentration of these additives. However, the basal plane presence $\left(\begin{array}{lll}0 & 0 & 2\end{array}\right)$ does not increase when formic acid and cyclohexylamine are added alone. Therefore, this behavior indicates a synergic effect of formic acid and cyclohexylamine in promoting the plan $\left(\begin{array}{lll}0 & 0 & 2\end{array}\right)$.

The microhardness and roughness measurements indicate that the addition of mixture of formic acid and cyclohexylamine in deposition bath results in a harder and more compact $\mathrm{Zn}$ coating, which favors the coating corrosion resistance.

In relation to the efficiency of deposition it was found that the addition of mixture of formic acid and cyclohexylamine increases the deposition current efficiency in comparison with the absence of additives and that effect increases with concentration of these additives.

\section{References}

1. Partasaradhy NV. Practical electroplating handbook. 1st ed. New Jersey: Prentice-Hall; 1989.

2. Mouanga M, Ricq L, Douglade J, Bercot P. Effects of some additives on the corrosion behaviour and preferred orientations of zinc obtained by continuous current deposition. J Appl Electrochem. 2007;37(2):283-94. http://dx.doi.org/10.1007/ s10800-006-9255-3.

3. Nakano H, Ura T, Oue S, Kobayashi S. Effect of preadsorption of organic additives on the appearance and morphology of electrogalvanized steel sheets. ISIJ Int. 2014;54(7):1653-60. http://dx.doi.org/10.2355/isijinternational.54.1653.

4. Szynkarczuk J, Drela I, Kubicki J. Electrochemical behaviour of chomium (III) in the presence of formic acid. Electrochim Acta. 1989;34(3):399-403. http://dx.doi.org/10.1016/00134686(89)87017-3.

5. Pedroza GAG, Souza CAC, Jesus MD, Andrade Lima LRP, Ribeiro DV. Influence of formic acid on the microstructure and corrosion resistance of $\mathrm{Zn}-\mathrm{Ni}$ alloy coatings by electrodeposition. Surf Coat Tech. 2014;258(15):232-9. http://dx.doi.org/10.1016/j. surfcoat.2014.09.022.

6. Soares ME, Souza CAC, Kuri SE. Corrosion resistance of a Zn-Ni electrodeposited alloy obtained with a controlled flow and gelatin additive. Surf Coat Tech. 2006;201(6):2953-9. http://dx.doi.org/10.1016/j.surfcoat.2006.06.006.

7. Pereira MS, Barbosa LL, Souza CAC, de Moraes ACM, Carlos A. The influence of sorbitol on zinc film deposition, zinc dissolution process and morphology of deposits obtained from alkaline bath. J Appl Electrochem. 2006;36(6):727-32. http://dx.doi.org/10.1007/s10800-006-9133-z.

8. Park CJ, Lohrengel MM, Hamelmann T, Pilaski M, Kwon HS. Grain-dependent Passivation of Surfaces of Polycrystalline Zinc. Electrochim Acta. 2002;47(21):3395-9. http://dx.doi. org/10.1016/S0013-4686(02)00221-9.

9. Hasegawa R. Glassy metals: magnetic, chemical and structural properties. Boca Raton: CRC Press; 1983.

10. Park H, Szpunar JA. 'The role of texture and morphology in optimizing the corrosion resistance of zinc-based electrogalvanized coatings'. Corros Sci. 1998;40(4-5):525-45. http://dx.doi. org/10.1016/S0010-938X(97)00148-0

11. Ashton RF, Hepworth MT. Effect of crystal orientation on the anodic polarization and passivity of zinc. Corrosion. 1968;244:50-3.

12. Youssef KM, Koch CC, Fedkiw PS. Influence of pulse plating parameters on the synthesis and preferred orientation of nanocrystalline zinc from zinc sulfate electrol. Electrochim Acta. 2008;54(2):677-83. http://dx.doi.org/10.1016/j. electacta.2008.07.048.

13. Choo RTC, Toguri JM, El-Sherik AM, Erb U. Mass transfer and electrocrystallization analyses of nanocrystalline nickel production by pulse plating. J Appl Electrochem. 1995;25(4):384403. http://dx.doi.org/10.1007/BF00249659.

14. Youssef KHMS, Koch CC, Fedkiw PS. Influence of additives and pulse electrodeposition parameters on production 
of nanocrystalline zinc from zinc chloride electrolytes. J Electrochem Soc. 2004;151(2):C103-11. http://dx.doi. org/10.1149/1.1636739.

15. Li MC, Jiang LL, Zhang WQ, Qian YH, Luo SZ, Shen JN. Electrodeposition of nanocrystalline zinc from acidic sulfate solutions containing thiourea and benzalacetone as additives. J Solid State Electrochem. 2007;11(4):549-53. http://dx.doi. org/10.1007/s10008-006-0194-z.

16. Saber K, Koch CC, Fedkiw PS. Pulse current electrodeposition of nanocrystalline zinc. Mater Sci Eng A. 2003;341(1-2):17481. http://dx.doi.org/10.1016/S0921-5093(02)00198-3.

17. Nayana KO, Venkatesha TV. Bright zinc electrodeposition and study of influence of synergistic interaction of additives on coating properties. J Ind Eng Chem. 2010;124:516-28.
18. Baik DS, Fray DJ. Electrodeposition of Zn from high acid zinc chloride solutions. J Appl Electrochem. 2001;31(10):1141-7. http://dx.doi.org/10.1023/A:1012290132379.

19. Mackinnon DJ, Brannen JM, Fenn PL. Characterization of impurity effect in zinc electrowinning from industrial acid sulphate electrolyte. J Appl Electrochem. 1987;17(6):1129-43. http://dx.doi.org/10.1007/BF01023596.

20. Robinson DJ, O'Keefe TJ. On the effects of antimony and glue on zinc electrocrystallization behaviour. J Appl Electrochem. 1976;6(1):1-7. http://dx.doi.org/10.1007/BF01058863.

21. Mackinnon DJ, Morrison RM, Mouland JE, Warren PE. The effects of antimony and glue on zinc electrowinning from Kidd Creek electrolyte. J Appl Electrochem. 1990;20(5):728-36. http://dx.doi.org/10.1007/BF01094298. 